Mudança organizacional:

implantação da Iniciativa Hospital Amigo da Criança

\author{
Organizational change: \\ the implementation of children-friendly hospitals
}

Shigeru Ricardo Sekyia ${ }^{1}$

Talita Ribeiro da Luz ${ }^{2}$
${ }^{1}$ Fundação H ospitalar do Estado de M inas Gerais. Alameda Álvaro Celso 100, Santa Efigênia. 30150-260 Belo Horizonte M G rshigeru@uol.com.br ${ }^{2}$ Faculdade $N$ ovos Horizontes.
Abstract Empirical evidences have pointed out the relevant role of breastfeeding to diminish infantile mortality. Children-friendly Hospitals (IHAC) is a worldwide action developed by the United Nations Children's Fund - UNICEF and by theWorld $\mathrm{H}$ ealth Organization, aiming to promote, protect and support breastfeeding and also prevent precocious weaning. The aim of the present study is to identify the main organizational changes which occurred in two hospitals, located in the State of M inas Gerais, Brazil that implemented IH AC. The organizational analysis carried out was based upon six perspectives, according to M otta's analytical chart that includes: strategic, structural, cultural, human, technological and political perspectives. A qualitative research was carried out, by using as a data gathering method the semi-structured interview, applied in all hierarchical levels. In order to interpret data, it was adopted the content analysis. In both cases, it could be concluded that the implementation of IHAC resulted in changes and improvement in the management of the organizations, due to the establishment of procedural patterns and staff training. It was verified that the cultural and technological changes occurred in a more intense manner and that the least perceived were the political and strategic changes.

Key words Organizational changes, Breastfeeding, Health management
Resumo Evidências empíricas apontam o relevante papel do aleitamento materno para a redução da mortalidade infantil. A Iniciativa H ospital Amigo da Criança (IH AC) é uma ação mundial, idealizada pelo Fundo das $\mathrm{N}$ ações U nidas para a Infância (UNICEF) e pela O rganização M undial da Saúde (OMS), que visa promover, proteger e apoiar a prática do aleitamento materno ea prevenção do desmame precoce. 0 objetivo desteartigo é identificar as principais mudanças organizacionais ocorridas em duas instituições hospitalares, localizadas em M inas Gerais, que implementaram a IH AC. A análise realizada baseou-se em seis perspectivas, tomando como base o quadro analítico de M otta: estratégica, estrutural, cultural, humana, tecnológica e política. Realizou-se uma pesquisa qualitativa, utilizando-se como mé todo de coleta de dados a entrevista semiestruturada, aplicada em todos os níveis hierárquicos. Para a interpretação dos dados, adotou-se a análise de conteúdo. $N$ os casos estudados, concluiu- se que a implantação da IH AC implicou mudanças e me Ihorias na gestão, principalmente pelo estabelecimento de padronização de procedimentose detreinamento de pessoal. Verificou-sequeas mudanças culturais e tecnológicas ocorreram de forma mais intensa e que as menos percebidas foram as mudanças políticas e as estratégicas.

Palavras-chave M udanças organizacionais, Aleitamento materno, Gestão em saúde 
Introdução

O leite materno, por suas características bioquímicas e por suas vantagens econômicas e psicossociais, representa, seguramente, o melhor alimento para as crianças nos primeiros meses de vida. Diversas evidências apontam o seu relevante papel na redução da morbimortalidade infantili-4. Com o objetivo de buscar mecanismos e ações que pudessem ser desenvolvidos para a proteção, promoção e apoio ao aleitamento materno, em 1990, a Organização Mundial de Saúde (OM S) e o Fundo das Nações Unidas para a Infância (UNICEF) realizaram um encontro na Itália, na cidade deFlorença, em quefoi idealizada a estratégia Iniciativa Hospital Amigo da Criança (IHAC). A IH AC consistena mobilização deprofissionais de saúde e funcionários de hospitais e maternidades para mudar as rotinas e condutas relacionadas à prevenção do desmame precoce. Porém, a implantação da IH AC podeimplicar desafios detoda ordem. Por basear-se em mudança de rotinas e condutas, pode gerar impactos na organização, exigindo maior esforço das pessoas para a sua implantação. Torna-se imprescindível que a avaliação de seus impactos não apenas se atenha aos aspectos técnicos, financeiros e epidemiológicos, mas considere igualmente questões ligadas à organização e a sua capacidade de aceitar esuportar as mudanças organizacionais decorrentes da implantação desta iniciativa2,3.

Para a Organização Pan-Americana da Saú de (OPAS), as sociedades mudam rapidamente, o que exige reformulações profundas nas formas de organização e de gestão dos hospitais para que se adaptem aos novos desafios sociais. Essas mudanças em hospitais são necessárias, especialmente porque os serviços públicos são burocráticos, suas estruturas são rígidas e verticais, encaram limitações legais e centralistas na gestão dos recursos financeiros ehumanos, esua culturainstitucional é muito pouco sensível às necessidades das pessoas e às mudanças do ambiente. Ainda segundo a OPAS, para se legitimarem esemanterem em um ambiente competitivo, os hospitais precisam desenvolver a capacidade de mudar. Portanto, a dificuldade para a construção do hospital do amanhã está na habilidade para aprender a mudar ? ou seja, na capacidadeinstitucional para aprender a escutar e a compreender ${ }^{2}$.

As organizações escolhidas para este estudo de caso são dois hospitais, sendo um público municipal e o outro filantrópico, ambos vinculados ao Sistema Ú nico de Saúde (SUS). Representam, portanto, um modelo bastante comum no cenário dos hospitais públicos no Brasil.
Nesta pesquisa, procurou-se identificar os impactos provocados pela implantação do programa Iniciativa Hospital Amigo da Criança em dois hospitais da rede pública. I dentificaram-se também as percepções dos profissionais de diferentes níveis (direção, gerências, supervisão e operacional) em relação aos elementos facilitadores do processo e às dificuldades e resistências enfrentadas.

\section{Revisão de literatura}

\section{Mudança organizacional}

N osúltimos anos, cresceu o debate acerca do tema "mudança organizacional", motivado pelas crescentes mudanças tecnológicas, políticas, econômicas e sociais pelas quais passam as organizações em todo o mundo. No entanto, poucos textos preocupam-se em definir esse conceito. M uitos são os aspectos a considerar na definição do conceito, como intensidade, tempo de reação e pessoas envolvidas. Wood ${ }^{5}$ apresenta um apanhado dos principais conceitos de mudança organizacional. Alguns percebem a mudança organizacional como uma atitude reativa - ou seja, fenômeno que ocorre como resposta a estímulos, tanto internos como externos. Entre eles estão Cook e Basil ${ }^{6}$, para quem a maioria das organizações muda em resposta às crises, sendo limitado o número de casos de atitudes proativas. Brown ${ }^{7}$ explora o impacto das inovações tecnológicasna mudança organizacional. Para ele, a geração contínua de produtos inovadores leva a empresa a adotar novas formas de trabalho, renovando as práticas administrativas. Waterman e Robert ${ }^{8}$ destacam a compreensão do fator renovação como central para a sobrevivência das empresas. As organizações, segundo eles, devem buscar uma convivência "feliz" com a mudança. A mudança deve fazer parte de seu cotidiano. Peters ${ }^{9}$ argumenta que uma das estratégias conhecidas para enfrentar um ambiente turbulento consiste em adotar a qualidade de classe mundial, inovação decurto prazo eflexibilidade, pois as melhores empresas não acreditam em excelência, mas apenas em melhoria contínua.

Outros consideram a mudança organizacional como uma atitude proativa e como processo planejado. Harari ${ }^{10}$ critica a adoção de planos que se apóiam em modas passageiras. Para ele, a mudança organizacional deve ser encarada como processo ecaracterizada pelo princípio demelhoria contínua. Huey ${ }^{11}$ apropria-se do conceito desenvolvido por Thomas Kuhn sobre paradigmas 
na ciência para mostrar como as mudanças são necessariamente acompanhadas por quebras de paradigmas. Adverte para a necessidade de que isso ocorra para que a inércia organizacional seja vencida e dêlugar a novos padrões. Este conceito tem angariado popularidade, em virtude das turbulências do ambienteeconômico eda necessidade demudanças rápidas dentro das organizações.

Alguns vêem a mudança organizacional de duas formas - reativa e proativa -, como Herzog $^{12}$, para quem a mudança no contexto organizacional engloba alterações fundamentais no comportamento humano, nos padrões de trabalho e nos valores, em resposta a modificações ou antecipando alterações estratégicas, de recursos ou de tecnologia.

Outro enfoque de mudança entende que as explicações sobre evolução, mudança edesenvolvimento das organizações se dão, basicamente, pela atenção aos fatores que determinam a identidade da organização e, consequentemente, as suas relações com o mundo exterior. M organ ${ }^{13}$ compara as organizações com os organismos vivos e com o cérebro. A primeira metáfora inspira-se, sobretudo, na biologia, para refletir sobre o funcionamento das organizações, tratando-as como sistema aberto ao ambiente. N esse ambiente, interagem clientes, colaboradores, concorrentes, fornecedores e agências governamentais, dentre outros, e nessa interação o sistema organizacional deve ser capaz de desenvolver respostas estratégicas apropriadas para sobreviver. Este raciocínio ajuda a esclarecer as relações entre a organização e seu meio, a importância da inovação e os aspectos de sobrevivência como meta vital. A metáfora sobre as organizações vistas como cérebro envolve duas perspectivas: a primeira explica que uma organização funciona como um sistema de processamento de informações, destacando a questão da cibernética e a capacidade de aprendizado; a segunda mostra as organizações como hologramas, o que significa fazer o todo em cada parte, criar conectividadee redundância, gerar, simultaneamente, especialização, generalização e auto-organização. Esta posição revela que vários cargos, departamentos e outras divisões dentro de uma organização criam estruturas de aten ção, interpretação e tomada de decisões queexercem influência crucial nas operações de toda organização.

Outras abordagens interessantes referem-se aos processos que estão sendo propostos e adotados para a implementação de mudanças nas organizações. Geralmente, esses processos respondem à necessidade de as organizações imple- mentarem mudanças para resolver questões estratégicas de natureza ambiental, estrutural, humana e tecnológica, entre as principais ${ }^{5}$.

M otta ${ }^{14}$ percebe a mudança organizacional como sendo a inovação por meio da intervenção social planejada, autossustentada e direcionada, que contrasta com as forças sociais espontâneas ou com provocações revolucionárias e com a visão evolutiva natural da mudança. Para M otta ${ }^{14}$, os diferentes modelos constroem teorias de mudança ao redor de focos específicos que concebem o fenômeno organizacional. Algumas das dimensões privilegiadas para a compreensão do fenômeno global demudanças apresentadas pelo autor são descritas a seguir:

. Estratégica: a organização évista como um sistema inserido em um contexto social, econômico e político, privilegiando-se sua forma de relacionar-se com a sociedade por meio de seus produtos e serviços. Considera-se que para mudar uma organização é necessário redefinir sua missão, objetivos eformas deidentificar eselecionar alternativas de ação;

. Estrutural: a organização é vista como um sistema de autoridade e responsabilidade, que define o âmbito de ação de cada pessoa e o consentimento e subordinação para cumprir funções estabelecidas. Pressupõe a definição prévia do papel formal dos funcionários como fator primordial de eficiência eeficácia. Conclui-seque, para mudar uma organização, é necessário alterar-se a forma pela qual se distribuem formalmente a autoridade e a responsabilidade;

- Tecnológica: enfatiza a divisão do trabalho, a especialização de funções e o tipo de tecnologia a ser empregada;

- Cultural: vê a organização como um conjunto devalores, crenças e hábitos coletivamente compartilhados, que a caracterizam e a distinguem de outras. Na mudança, considera-se importante substituir a programação coletiva, na busca de um novo sentido de identidade, como se fosse um empreendimento coletivo para alterar os valores das pessoas. Como o objetivo da mudança é internalizar novos valores, considera-se o treinamento um instrumento importante desse processo de socialização;

- Política: a organização éconsiderada um sistema de poder em que os indivíduos e grupos procuram ter maior influência no poder decisório. 0 poder é visto como um fim em si mesmo ou um instrumento para que determinadas idéias prevaleçam sobre outras. Mudar uma organização passa a ser uma interferência nas formas como se articulam e se agregam os interesses e 
como se equilibra o poder entre interesses individuais coincidentes e conflitantes, incluindo a negociação interna e a solução de conflitos;

. Humana: esta perspectiva concentra-se na ligação do indivíduo com o trabalho, ressaltando os fatores de motivação e de liderança, e os demais fatores psicossociais subjacentes às prescrições institucionais e linhas de autoridade formalmente estabelecidas. Considera-se que, para mudar uma organização, énecessário alterar atitudes, comportamentos e a forma de participação dos indivíduos, mediante o incentivo à colaboração, às práticas de motivação, à liderança, à reconstrução do sistema de recompensas, de carreira e ao aperfeiçoamento pessoal.

Algumas décadas atrás, a mudança era vista como perturbação da ordem ou qualquer ação contestadora da autoridade, eliminando-se as resistências pela simples tentativa de submeter as pessoas à nova ordem estabelecida. Atualmente, a resistência à mudança tende a ser vista como algo tão natural como a própria mudança, pois está presente em todas as decisões e pode ser observada na utilização do uso de recursos organizacionais para manifestar oposição, bloqueio, retardamento e proposição de alternativas ${ }^{14}$.

De acordo com 0 autor, a resistência significa o exercício do pensamento diferente, sendo fonte decrítica ede criatividade. Outros autores consideram-na positiva pois fornece certo grau de estabilidade e previsi bilidadeao comportamento ${ }^{15}$.

\section{Iniciativa H ospital Amigo da Criança}

A Iniciativa H ospital Amigo da Criança (IHAC) é uma ação mundial, idealizada em 1990, pelo Fundo das Nações Unidas para a Infância (UN ICEF) e pela Organização Mundial da Saúde (OMS). Visa promover, proteger e apoiar a prática do al eitamento materno, a fim de reduzir o desmame precoce e suas consequências sobre a morbimortalidade infantil ${ }^{3}$.

Segundo Lamounier ${ }^{16}$, para que uma maternidade ou um hospital com leitos obstétricos se transforme em um "Hospital Amigo da Criança", faz-se necessário mobilizar os funcionáriose os profissionais de saúde para gerar mudanças em condutas e rotinas, visando prevenir o desmame precoce. Tal fenômeno resulta deuma complexa interação de fatores socioculturais, por exemplo, o processo de industrialização, o surgimento edivulgação de leites industrializados, com a respectiva adesão de profissionais de saúde à prescrição da alimentação artificial, a inserção da mulher no mundo do trabalho ea adoção nas maternidades de medidas pouco incentivadoras do aleitamento materno. Com vistas à redução do desmame precoce e com base na modificação de rotinas hospitalares inadequadas à prática da amamentação, foram normatizadas pela O M S e UNICEF as orientações abaixo, denominadas "Dez passos para o sucesso do aleitamento materno":

19) Ter uma norma escrita sobre al eitamento materno, que deverá ser rotineiramente transmitida a toda equipe de cuidados de saúde;

2o) Treinar toda a equipe de cuidados desaúde, capacitando-a para implementar a referida norma;

3o) Informar todas as gestantes sobre as vantagens e o manejo do aleitamento materno;

4ํ) Ajudar as mães a iniciar a amamentação na primeira meia hora após o parto;

5) M ostrar às mães como amamentar e como manter a lactação, mesmo se vierem a ser separadas de seus filhos;

6) Não dar aos recém-nascidos nenhum outro alimento ou bebida além do leite materno, a não ser que seja prescrito pelo médico;

70) Praticar o alojamento conjunto (permitir que mães e bebês permaneçam juntos 24 horas por dia);

8o) Encorajar o aleitamento sob livredemanda;

9o) Não dar bicos artificiais ou chupetas a crianças amamentadas no peito;

10ㅇ) Encorajar a formação degrupos deapoio à amamentação, para onde as mães devem ser encaminhadas, logo após a alta do hospital ou ambulatório.

Diferentemente dos demais países, para o Brasil, o M inistério da Saúde estabeleceu, pela Portaria 756, além dos dez passos, os dez pré-requisitos ${ }^{17}$, indicadores da qualidade da assistência à mulher e à criança, no processo de avaliação:

10) Comprovar cadastramento no Cadastro Nacional dos Estabelecimentos deSaúde(CNES);

2o) Comprovar cumprimento à Norma Brasileira de Comercialização de Alimentos para Lactentes e Crianças na Primeira I nfância;

3o) Não estar respondendo à sindicância no Sistema Ú nico de Saúde;

4ํ) Não ter sido condenado judicialmente, nos últimos dois anos, em processo relativo à assistência prestada no pré-parto, parto, puerpério eperíodo deinternação em unidade de cuidados neonatais;

5) Dispor de profissional capacitado para a assistência à mulher e ao recém-nascido no ato do parto; 
60) Garantir, a partir da habilitação, que pelo menos $70 \%$ dos recém-nascidos saiam de alta hospitalar com o Registro de Nascimento Civil, comprovado pelo Sistema de Informações hospitalares;

70) Possuir comitêatuante de investigação de óbitos maternos, infantis e fetais;

8o) A presentar taxa percentual de cesarianas, conforme a estabelecida pelo gestor estadual/ municipal;

9o) Apresentar tempo de permanência hospitalar mínimo de 24 horas para parto normal e de 48 horas para parto cesariana;

10 ) $)$ Permitir a presença de acompanhante no alojamento conjunto.

Estudos realizados no Brasil e no Chile têm mostrado o impacto da IHAC no aumento da duração do al eitamento materno. No Chile, Valdés et al. ${ }^{18}$ acompanharam crianças nascidas em um Hospital Amigo da Criança (HAC), comparando-as com outras que nasceram em um hospital tradicional, em Santiago. A prevalência do al eitamento materno exclusivo nos primeirosseis meses de vida foi de $66,8 \%$ naquelas que nasceram no $\mathrm{HAC}$, contra $23,3 \%$ nas que nasceram no hospital tradicional ${ }^{18}$. No Brasil, estudo semelhante foi realizado por Fiedler ${ }^{19}$, comparando um H AC em Santos (SP), com outro hospital tradicional (controle), porém que atuava de maneira tradicional, ou seja, sem incentivo ao al eitamento materno. Constatou-se que a mediana de amamentação com leite materno exclusivo foi de 75 dias, contra 22 dias. Isso representaria um benefício de 53 dias em amamentação se o programa fosse instituído no hospital-controle.

Vários estudos demonstram que é possível mel horar as práticas que estimulam o al eitamento materno nas maternidades com o treinamento de dezoito horas da IHAC, tendo como base 0 cumprimento dos "dez passos" para o sucesso do aleitamento materno $17,18,20$. Informações divulgadas pelo PNIAM /U NICEF mostraram que a adoção dos "dez passos" e o trabalho de incentivo ao al eitamento materno resultaram em significativo aumento dos índices de amamentação em várias localidades no Brasil. Em Fortaleza (CE), na M aternidade Escola Assis Chateaubriand, uma pesquisa realizada no período de junho de 1993 a junho de 1994 revel ou uma prevalência de aleitamento materno exclusivo de $73 \%$ no primeiro mês, $62 \%$ nos dois meses, $51 \%$ nos três meses, $44 \%$ nos quatro meses ede $38 \%$ entre cinco e seis meses. Dados de pesquisas realizadas no Estado do Ceará mostraram taxas de $33 \%$ de aleitamento materno exclusivo nos trinta dias e de $21 \%$ nos sessenta dias. No Distrito Federal, os níveis de aleitamento materno exclusivo foram de 58 dias, aleitamento materno predominante em 92 dias eamamentação mista em 101 dias. 0 programa de incentivo ao aleitamento materno desenvolvido na maternidade tem contribuído para reduzir as taxas de morbimortalidade infantil. Em Joinville (SC), na M aternidade Darcy Vargas, conforme mostrado em uma pesquisa, os índices de aleitamento materno exclusivo no período de quatro a seis meses foi de $22 \%$, superior ao da média nacional. Em Feira de Santana (BA), um estudo de junho de 1996 envolvendo 3.898 crianças com idade inferior a dois anos revelou taxas de $45 \%$ al eitamento materno exclusivo na faixa etária de 0-3 meses e de $45,4 \%$ na faixa etária de 12-15 meses. A mediana de duração do aleitamento materno foi denovemeses. A experiência e os resultados descritos demonstram que a IH AC tem contribuído muito para a meIhoria dos índices de incidência e de prevalência do aleitamento materno no país.

\section{Procedimentos metodológicos}

Para atingir os objetivos propostos, optou-se pela pesquisa qualitativa, contemplando uma amostra de dois hospitais, pelo método do estudo de caso, objetivando captar com a maior fidelidade possível as percepções de pessoas das organizações pesquisadas que vivenciaram o processo de implantação da Iniciativa Hospital Amigo da Criança. A abordagem qualitativa foi selecionada como método de pesquisa, tendo em vista que o estudo tem natureza descritivo-interpretativa, visando apreender as perspectivas e interpretações das pessoas a respeito de uma realidade vivenciada.

Os dois hospitais selecionados são vinculados ao Sistema Ú nico de Saúde (SUS), sendo um público, localizado na região metropolitana de Belo H orizonte, e o outro filantrópico, localizado no centro-oeste mineiro. 0 critério principal utilizado para a seleção dos dois hospitais foi a facilidade de acesso e aprovação do estudo pelos Comitês de Ética. Além disso, buscaram-se hospitaisquejátivessem obtido a certificação há mais de um ano, ou seja, que já tivessem incorporado esse processo em suas rotinas.

Todos os entrevistados concordaram em participar do estudo e assinaram o termo de consentimento livreeesclarecido.

A amostra foi composta por seis membros do corpo gerencial e seis funcionários de nível 
operacional de cada hospital, que participaram da implementação do programa I niciativa H ospital Amigo da Criança. As entrevistas em cada hospital foram realizadas com diretor geral, gerente da enfermagem, gerente da neonatologia (pediatria), líder (responsável) no processo de implantação da IHAC, gerente de recursos humanos, supervisor de enfermagem e seis funcionários da assistência direta ao binômio mãe filho.

As técnicas utilizadas para a coleta de dados foram: (a) análise documental: livros, revistas, informativos, organogramas, relatórios e outros documentos internos; $e$ (b) entrevista semiestruturada com questões abertas, o que permitiu ao entrevistador entender e captar a perspectiva dos participantes da pesquisa. As entrevistas foram realizadas individualmente, utilizando dois roteiros básicos, sendo um para o pessoal de direção ou de nível gerencial e outro para o pessoal denível operacional.

A observação dos ambientes pesquisados subsidiou e enriqueceu as análises e as conclusões obtidas. Com base nas informações coletadas nas entrevistas e nas observações posteriores, realizou-se a análise de dados, que se baseou na técnica de análise de conteúdo ${ }^{21}$. N esta fase, para subsidiar a análise, foram consideradas as perspectivas de análise organizacional apresentadas por M otta, a partir das quais foram elencadas as principais categorias de mudanças organizacionais.

\section{Descrição dos hospitais pesquisados}

O hospital A, localizado em Contagem (M G), tem capacidade de realizar cerca detrês mil atendimentosequinhentas internações por mês. Conta com 89 leitos, dos quais vinte são destinados às unidades de tratamento neonatal.

0 processo deimplantação da IH AC no H ospital $A$, desde o lançamento formal até a data da entrega do título, durou cinco anos e 11 meses (20/06/2000 a 25/05/2005). Para a coordenação do processo, constituiu-se um comitê (composto por três enfermeiros, assistente social, duas auxiliares de enfermagem, nutricionista, duas psicólogas, pediatra, terapeuta ocupacional e duas técnicas de nutrição), o qual geriu o processo de implantação, seguindo um planejamento de atividades.

O H ospital B, localizado na cidade de Pará de M inas (MG), atende usuários do SUS, convênios, pacotes e particulares, sendo a clientela do SUS em número superior às demais. Possui 135 leitos, sen- do 97 para o SUS e o restante para particulares e convênios. Atualmente, possui 360 funcionários.

0 processo de implantação da IH AC no H ospital B, desdeo seu lançamento formal até a data da avaliação, durou três anos (11/06/2001 a 31/ 03/2004). A implementação da IH AC foi uma decisão estratégica - portanto, este assunto era acompanhado pela diretoria e pela comissão designada pelo diretor para a implantação da Iniciativa Hospital Amigo da Criança. A comissão era composta de médicos, equipe de enfermagem, odontóloga, psicóloga e fonoaudióloga.

\section{Resultados}

A análise dos dados revelou que as mudanças organizacionais citadas com maior frequência foram aquelas denominadas de "mudanças culturais" e "mudanças tecnológicas". O Q uadro 1 relaciona as mudanças culturais.

O Quadro 2 relaciona as mudanças tecnológicas.

Além das mudanças culturais e tecnológicas, algumas mudanças estruturais/políticas importantes também foram relatadas nos hospitais pesquisados, conforme se segue no Quadro 3.

Quanto aos aspectos relacionados à gestão de pessoas, as mudanças foram frequentes e ficaram concentradas nos efeitos da sistematização da atividade de treinamento, que constitui um dos requisitos da IHAC, implicando a meIhoria da qualificação do pessoal dos hospitaise, por consequência, aumentando o rigor na seleção e recrutamento de novos funcionários. Foram também relatados alguns aspectos relativos à melhoria do clima organizacional. 0 Q uadro 4 mostra as mudanças mais significativas relacionadas à gestão de pessoas.

Os menores impactos percebidos pelas pessoas em função da implantação da IH AC dizem respeito aos aspectos estratégicos, em relação aos quais foram citadas poucas mudanças. 0 maior ben efício foi autilização do título “H ospital Amigo da Criança" como fator de diferenciação do hospital no mercado de atuação e como um instrumento de marketing (Quadro 5).

Conforme observado, a implantação da IHAC constitui um processo de mudança bastante abrangente, queinfluencia diferentes aspectos de uma organização, embora a maioria das organizações não realize análise prévia do alcance de tal iniciativa e sequer se prepare para enfrentar as possíveis dificuldades decorrentes dessas mudanças. 
Quadro 1. M udanças culturais observadas nos hospitais pesquisados.

\begin{tabular}{|c|c|}
\hline \multicolumn{2}{|r|}{ Mudanças culturais } \\
\hline Relacionadas com crenças & $\begin{array}{l}\text { - Conscientização da necessidade de criar rotinas e segui-las } \\
\text { diariamente. }\end{array}$ \\
\hline Novas atitudes & $\begin{array}{l}\text { - Maior confiança nos funcionários. } \\
\text { - M aior comprometimento das pessoas com a organização. } \\
\text { - Maior valorização dos pacientes. } \\
\text { - Maior organização dos setores. } \\
\text { - M aior dependência das chefias e de outros profissionais. } \\
\text { - Responsabilidade de todos no apoio ao aleitamento materno. }\end{array}$ \\
\hline Incorporação de novos valores & $\begin{array}{l}\text { - Conscientização da importância de treinamentos periódicos. } \\
\text { - Conscientização da necessidade de registrar as atividades. } \\
\text { - Trabalho em equipe. }\end{array}$ \\
\hline Incorporação de novos rituais & $\begin{array}{l}\text { - Atividade de preparação para avaliação. } \\
\text { - Documentação dos treinamentos. } \\
\text { - Sistemática de ações coletivas, buscando agir nas causas. } \\
\text { - Comemoração de datas. }\end{array}$ \\
\hline Relações interpessoais & $\begin{array}{l}\text { - M aior diálogo. } \\
\text { - Maior companheirismo. } \\
\text { - M enos individualismo. } \\
\text { - Redução de conflitos. }\end{array}$ \\
\hline $\begin{array}{l}\text { Comportamento grupal } \\
\text { e intergrupal }\end{array}$ & $\begin{array}{l}\text { - M aior aproximação e integração entre os setores. } \\
\text { - M aior abertura para mudanças. } \\
\text { - M aior flexibilidade das pessoas. }\end{array}$ \\
\hline $\begin{array}{l}\text { Comunicação interna } \\
\text { e integração entre áreas }\end{array}$ & $\begin{array}{l}\text { - M aior troca de informações entre setores. } \\
\text { - M aior formalização das comunicações (exemplos: mural, cartazes). } \\
\text { - M aior fluxo de informações para o pessoal de nível operacional. }\end{array}$ \\
\hline Estilo de liderança & - Relacionamento mais aberto com as chefias. \\
\hline
\end{tabular}

Fonte: Dados da pesquisa.

Quadro 2. M udanças tecnológicas observadas nos hospitais pesquisados.

\begin{tabular}{|l|l|}
\hline \multicolumn{2}{|c|}{ Mudanças tecnológicas } \\
\hline Aquisição de máquinas e equipamentos & $\begin{array}{l}\text { - Aquisição de ordenhadeira. } \\
\text { - Banco de leite. } \\
\text { - Respirador. } \\
\text { - Poltronas para sala de coleta. } \\
\text { - Freezer. } \\
\text { - Caixa térmica. }\end{array}$ \\
\hline Padronização de processos & $\begin{array}{l}\text { - Norma escrita em todos os setores. } \\
\text { - Documentação de treinamentos. }\end{array}$ \\
\hline Incorporação de novos processos & $\begin{array}{l}\text { - Foi incorporado um banco de leite. } \\
\text { - Novos parceiros: D oulas e Amigas do Peito. }\end{array}$ \\
\hline M udanças no leiaute & $\begin{array}{l}\text { - M ais cartazes. } \\
\text { - Eliminação do berçário de admissão. } \\
\text { - Banco de leite humano. }\end{array}$ \\
\hline
\end{tabular}

Fonte: Dados da pesquisa. 
Quadro 3. M udanças estruturais/políticas observadas nos hospitais pesquisados.

\begin{tabular}{|l|}
\hline \multicolumn{1}{|c|}{ Mudanças estruturais/políticas } \\
\hline - Criação de uma comissão de aleitamento materno. \\
\hline - Alteração no processo decisório: o comitê passa a sugerir mudanças. \\
\hline - Criação de novos setores: banco de leite humano e alojamento materno. \\
\hline - Maior autonomia e responsabilidade do nível operacional. \\
\hline
\end{tabular}

Fonte: Dados da pesquisa.

Quadro 4. M udanças em gestão de pessoas observadas nos hospitais pesquisados.

\begin{tabular}{|l|l|}
\hline \multicolumn{2}{|c|}{ Mudanças relativas à gestão de pessoas } \\
\hline Recrutamento e seleção & $\begin{array}{l}\text { - Perfil exigido para novos funcionários: competências para } \\
\text { atendimento humanizado e voltado para o aleitamento } \\
\text { materno. }\end{array}$ \\
\hline Capacitação de pessoal & $\begin{array}{l}\text { - Sistematização de treinamentos necessários. } \\
\text { - Aumento da capacitação. }\end{array}$ \\
\hline Comprometimento do pessoal & $\begin{array}{l}\text { - Aumento do nível de exigências e cobranças entre os } \\
\text { profissionais e setores. }\end{array}$ \\
\hline Forma de remuneração e recompensas & $\begin{array}{l}\text { - Pagamento de horas extras para os treinamentos de } \\
\text { funcionários. }\end{array}$ \\
\hline Clima organizacional & $\begin{array}{l}\text { - Aumento da amizade e companheirismo. } \\
\text { - As pessoas sentiram-se valorizadas. }\end{array}$ \\
\hline
\end{tabular}

Fonte: Dados da pesquisa.

Quadro 5. M udanças em aspectos estratégicos observados nos hospitais pesquisados.

\begin{tabular}{|l|}
\hline \multicolumn{1}{|c|}{ Mudanças estratégicas } \\
\hline - Uso do título como instrumento de marketing. \\
\hline - Equiparação com outros hospitais que já possuíam o título. \\
\hline - Diferenciação em relação a outros hospitais que não possuíam o título. \\
\hline - Organização e expansão da atuação: Banco de leite e Doulas. \\
\hline
\end{tabular}

Fonte: Dados da pesquisa.

Embora algumas organizações possam supor que o tempo para implantar a IHAC dependa diretamente do número de funcionários, verificousequeesse tempo érelativamente longo. 0 Hospital A apresentou maior período deimplantação da IHAC, o que provavelmente está associado a suas várias iniciativas para manter o pessoal mobilizado e comprometido ao longo de todo o processo.

O Quadro 6 mostra o tempo que os hospitais pesquisados precisaram para implantar a IHAC, o número defuncionários eo número de leitos que apresentam. 
Quadro 6. Número de funcionários, número de leitos e o tempo para implantar a IHAC.

\begin{tabular}{|l|c|c|}
\hline \multicolumn{1}{|c|}{ Dados } & Hospital A & Hospital B \\
\hline Tempo de implantação & 4 anos e 11 meses & 3 anos e 9 meses \\
\hline Número de funcionários & 390 & 360 \\
\hline Número de leitos & 89 & 135 \\
\hline
\end{tabular}

Fonte: Dados da pesquisa.

Analisando-se a forma utilizada pelos hospitais para implantar a IHAC, constatou-se em ambosa existência deum grupo responsável pela criação do processo, em geral, denominado comitê, composto por pessoas que realizaram 0 curso de dezoito horas em al eitamento materno.

Apontado como elemento facilitador nos hospitais pesquisados, o comprometimento da al ta administração constitui condição fundamental para o êxito da implantação da IHAC, uma vez que o processo como um todo demanda a liberação de recursos variados, o incentivo e, até mesmo, em certos casos, a imposição de parte de quem detinha o poder máximo na organização.

Foi citada a influência da obtenção do título "Hospital Amigo da Criança" para a melhoria da imagem do hospital no mercado. Essa constatação justifica-se pelo fato de uma pequena parcela de organizações possuir o título, diante do grande número de hospitais existentes, conferindoIhes, efetivamente, um diferencial e, também, pelo fato de o pessoal da alta administração poder explorar a conquista desse reconhecimento de forma a produzir impacto na comunidade.

N os hospitais pesquisados, as influências decorrentes da implantação da IH AC no desempenho e nos resultados das organizações mostraram-se mais localizadas em aspectos relacionados aos processos de trabalho. Foram observadas melhorias significativas na redução de consumo de leite em pó em ambos os hospitais, com a consequente redução de custos e a melhoria da qualidade do serviço. Os dois hospitais, no que se refere aos resultados financeiros, não relataram aumento de faturamento ou lucratividade.

Alguns aspectos decorrentes da implantação da IH AC qualificados pelos entrevistados como negativos encontram-se relacionados no Quadro 7.

Aspecto interessante lembrado pelo pessoal denível operacional está relacionado com as auditorias periódicas de certificação e de manuten-
Quadro 7. Aspectos negativos da implantação da IHAC.

\begin{tabular}{|l|}
\hline Aspectos negativos \\
\hline - Desgaste decorrente do processo de \\
implantação (resistência). \\
\hline - Carga de trabalho adicional. \\
\hline - Aumento das exigências internas e externas. \\
\hline - Desconforto e temor pelas avaliações. \\
\hline
\end{tabular}

Fonte: Dados da pesquisa.

ção, as quais geram certo clima de desconforto e temor nas pessoas.

Nos hospitais pesquisados, a resistência às mudanças foi mais visível por parte da categoria médica. Em situações de resistências irreversíveis, foi citado o caso de afastamento de um funcionário como forma de dar continuidade ao processo.

No período pós-certificação, as maiores dificuldades constatadas nas organizações pesquisadas prenderam-se à manutenção do título. Essa constatação demonstra que algumas rotinas da IHAC não espelham exatamente a realidade dos hospitais ou constituem processos novos, ainda não totalmente incorporados à rotina das organizações.

Os entrevistados relataram um período de preparação intensa, que antecede as auditorias periódicas de manutenção realizadas pela Secretaria Estadual de Saúde e pelo M inistério da Saúde. N esse período, ocorrem uma revisão geral dos processos que compõem a IH AC euma rememoração de conhecimentos específicos, que podem ser alvo de questionamento por parte do auditor. Também ficaram evidenciados pelo pessoal dos hospitais sentimentos de medo, nervosismo, desconforto e, em al guns casos, até pânico.

As auditorias periódicas da Secretaria Estadual da Saúde e do M inistério da Saúde foram 
referidas como os principais instrumentos para garantir a manutenção da IH AC. M uito embora tenham sido relatadas como al go temido, requerendo uma preparação prévia intensa, as auditorias foram consideradas por muitos como um "mal necessário", assegurando a perpetuação da IH AC na organização.

Outras formas relatadas para manter a IH AC foram: real ização de treinamentos periódicos para reforçar os conceitos e práticas; reuniões periódicas e promoção de alguns fóruns de acompanhamento, como ComitêPermanente deAleitamento Materno.

\section{Conclusão}

Nos dois casos estudados, conclui-se que a implantação da IH AC provocou mudanças na organização em todas as categorias pesquisadas: estruturais, políticas, culturais, tecnológicas e relacionadas à gestão de pessoas. Entretanto, com base nos relatos das mudanças verificadas nas duas organizações, conclui-se que as mudanças culturais e tecnológicas foram as de maior impacto.

Do ponto de vista das mudanças tecnológicas, as constatações devem-se ao fato de que a IH AC possui um forte foco no controle dos processos que venham a afetar a qualidade dos serviços da organização, prendendo-se à análise das melhorias, às aquisições de equipamentos, à mudança de leiaute, as quais estão atreladas aos aspectos tecnológicos da uma organização.

A nova forma de organização, baseada primordialmente na padronização das rotinas de incentivo ao aleitamento materno e ao monitoramento do mesmo, traz como consequência algumas mudanças culturais, como a valorização da documentação e dos treinamentos, bem como o maior intercâmbio de informações entre os membros da equipe.

As mudanças de caráter estrutural foram também observadas nos dois casos, vinculadas, basicamente, à criação de um órgão ou comitê para coordenar a implantação e o acompanhamento da IHAC.

Mudanças estratégicas foram de pouco impacto nas organizações analisadas, afetando mais o posicionamento dos hospitais perante o mercado, pelo fato de conquistarem um título almejado por várias organizações. Essa constatação deve-seao fato deaIHAC não ter sido concebida para alterar diretamentea relação entre a organização como um todo e o seu ambiente e de suas transformações principais estarem focadas nos aspectos internos.

Quanto às mudanças relacionadas à gestão de pessoas, nos dois casos, observou-se a implementação de treinamentos periódicos, assim como a promoção de programas de capacitação do pessoal, o que está formalmente expresso em requisito específico daIH AC. O bservou-seo estabelecimento da necessidade de manter pessoal qualificado para entender e executar os requisitos da norma.

Aindanos dois casos, constatou-sequea percepção do pessoal de nível operacional quanto à implementação da IH AC foi muito positiva. Praticamente todas as pessoas entrevistadas referiram-sesomentea aspectos benéficos, comparando a situação de pós-certificação com a anterior como uma evolução significativa, que serviu para melhorar seu local, sua rotina de trabal ho e seu relacionamento interno.

Praticamente todas as pessoas entrevistadas nos dois hospitais referiram-se aos médicos como os mais resistentes às mudanças.

Os dois casos analisados apresentam muitas similaridades na maioria dos aspectos enfocados nas entrevistas. Entretanto, uma particularidade foi observada apenas no H ospital B, no qual se relataram mudanças em relação à gestão de pessoas, passando a exigir um perfil para admissão de funcionários. Isso não ocorreu no H ospital $A$, porque é uma instituição pública municipal eporque seus funcionários são efetivados por concurso público.

Esses resultados trazem como reflexão a necessidade de um apoio mais efetivo e continuado por parte dos profissionais de saúde e gestores com relação à prática do aleitamento materno exclusivo elHAC.

Uma das principais limitações deste estudo está no fato de apoiar-se na estratégia de estudo de casos, inviabilizando a possibilidade de generalização dos resultados para as populações ou para outros hospitais que adotaram a IHAC. 


\section{Colaboradores}

\section{SR Sekyia trabalhou na concepção teórica, ela- boração e redação do texto eTR Luz supervisio- nou todas as etapas de concepção e elaboração e trabalhou na redação final do artigo.}

\section{Referências}

1. Gartner LM, M orton J, Lawrence RA, Naylor AJ, O' Hare D, Schanler RJ, Eidelman AI, American Academy of Pediatrics Section of Breastfeeding. Breastfeeding and the use of human milk. Pediatrics 2005; 115:496-506.

2. Organização Pan-Americana da Saúde. A transformação da gestão de hospitais na América Latina e Caribe. Brasília: OPAS; 2004.

3. PNIAM/UNICEF. Boletim Nacional Iniciativa Hospital Amigo da Criança 1995; 2(12).

4. Victora CG, Smith PG, Vaughan JP, Nobre LC, Lombarde $C$, Teixeira AM, Fuchs SM, M oreira LB, Gigante LP, Barros FC. Evidence for protection by breast-feeding against infant deaths from infections diseases in Brazil. Lancet 1987; 2:319-322.

5. Wood Jr. T, organizador. Mudança organizacional. São Paulo: Atlas; 2004.

6. Cook CW, Basil D. The management of change. Maidenhead: M cGraw-Hill; 1974.

7. Brown J. Research that reinvents the corporation (Xerox Palo Alto Research Center). Harvard Business Review 1991; 69:102-111.

8. Waterman Jr. RH. O fator renovação: como os meIhores conquistam e mantêm a vantagem competitiva. São Paulo: Harbra; 1989.

9. Peters T. Prosperando no caos. São Paulo: Harbra; 1989.

10. Harari O. Let's end the program-of-the-month syndrome (approaching change as focused process, not as collage of programs). M anagement Review 1991; 80(8):46.

11. Huey J. Nothing is impossible (paradigm shiftting). Fortune 1991; 124(7):90-94.

12. Herzog JP. People: the critical factor in managing change. Journal of Systems M anagement 1991; 42(3):6-11.
13. M organ G. Imagens da organização. São Paulo: Atlas 2006.

14. Motta PR. Transformação organizacional: a teoria e prática de inovar. 5a ed. Rio de Janeiro: Qualitymark; 2004.

15. Robbins StP. Comportamento organizacional. 9a ed. São Paulo: Prentice Hall; 2002.

16. Lamounier JA. Experiência Iniciativa Hospital Amigo da Criança. Revista Associação M édica Brasileira 1998; 44:319-324.

17. Brasil. M inistério da Saúde. Portaria no 756/GM de 16 de dezembro de 2004. 10 exigências além dos 10 passos. Diário Oficial da U nião 2004; 17 dez.

18. Valdes V, Perez S, Labbok M, Pugin E, Zambramo I, Catalan S. The impact of a hospital and clinicbased breastfeeding promotion programme in a middle class urban environment. J Trop Pediatr 1993; 39:142-151.

19. Fiedler J. Cost of the breastfeeding promotion program in the Guilherme Alvaro Hospital of Santos, Brazil. Washington, D.C.: USAID, LAC; 1995.

20. Cattaneo A, Buzzetti R. Effect on rates of breast feeding of training for the Baby Friendly Hospital Iniciative. Br M ed J 2001; 323:1358-1362.

21. Roesch SM A. Projetos de estágio do curso de administração: guia para pesquisas, projetos, estágios e trabaIhos de conclusão de curso. São Paulo: Atlas; 1996.

Artigo apresentado em 08/01/2008

Aprovado em 06/05/2008 